International Journal of Social Science and Economic Research

ISSN: 2455-8834

Volume: 05, Issue: 02 "February 2020"

\title{
THE INFLUENCE OF PRICE LIMITS CHANGE ON STOCK MARKET BASED ON SIMULATION METHOD
}

\author{
Hengyu Yao \\ College of Economics and Management, Nanjing University of \\ Aeronautics and Astronautics, Nanjing 210016, China
}

DOI: 10.46609/IJSSER.2020.v05i02.006 URL: https://doi.org/10.46609/IJSSER.2020.v05i02.006

\begin{abstract}
Based on the simulation results of prices and yields using the artificial stock market model, the paper investigates the influence of price limits change on stock market in the perspective of volatility and liquidity. And through the analysis of the simulation results, we found that only the more stringent price limits (e.g. 5\%) can effectively reduce the volatility of the stock market, and at this time there is no significant difference in liquidity between the market with stringent price limits and the market without price limits. While market volatility will increase significantly with widening of the price limits, market liquidity will improve significantly. However, it is noteworthy that if the change of price limits is not large enough especially when prior price limits are set $10 \%$ or more, the increase in liquidity may not be significant. Volatility and liquidity basically remain stable under price limits of $20 \%$ or more.
\end{abstract}

Keywords: Price limits; Volatility; Liquidity; Simulation

\section{INTRODUCTION}

Price limit is a kind of price stabilization mechanism adopted by financial markets in order to curb excessive speculation and herd behavior. It's designed to prevent violent fluctuations and severe deviation from the fundamental value of stock prices, thus reducing financial risk. According to Kim and Park (2010) $)^{[1]}$, more than half (23) of the 43 different countries and territories for which primary market data are available have price limits, thresholds range from a minimum value of 5\% (e.g., Australia, Egypt and Turkey) to a maximum value of $50 \%$ or even $60 \%$ (e.g., Philippines and Japan).

Nowadays, the mainstream trend is to gradually widen the price limits. For example, Taiwan and South Korea respectively announced the widening of the price limits in June 2015, the former 


\section{International Journal of Social Science and Economic Research}

ISSN: $2455-8834$

Volume: 05, Issue: 02 "February 2020"

changed from $7 \%$ to $10 \%$ and the latter from $15 \%$ to $30 \%$. From the perspective of the regulators, the widening of price limits is a positive sign that the trading system as a whole is moving closer to mature capital markets abroad, to ensure that market liquidity, flexibility and professionalism can be enhanced at the expense of increasing market volatility.

In response, Kim and Jun (2019) ${ }^{[2]}$, Lien et al.(2019) ${ }^{[3]}$ based on the daily data before and after the change of price limits, which are respectively from the Korean Stock Exchange and the Taiwan Stock Exchange, draw the conclusion that the market volatility increases with the widening of the price limits through the empirical research. The difference between this two articles is that the latter takes more details into account, specifically when it comes to the effects of price limits change on stock market, the case not only considers volatility, but also bid-ask spread, market depth, order execution speed and order completion rate. Eventually, the empirical results show that when the price limit is widened, on one hand, the bid-ask spread and daily volatility increase significantly while the market depth decreases, on the other hand, the order execution speed accelerates and the order completion rate is higher, but the overall impact of the price limits change is more positive than negative.

However, the relevant empirical research has always been unable to overcome one point, that is, there is no control group without price limits, that is, we cannot confirm the effectiveness of price limits by comparing stock markets under different levels of price limits but with the same other conditions. The appearance of simulation method solves this problem well. Westerhoff $(2003)^{[4]}$ first tried to test the effectiveness of price limits by building an agent-based Artificial Stock Market (ASM), which proved that price limits can be carried out to reduce volatility, as well as to reduce the deviation of the price from its fundamental value. Ever since, Chiarella and Iori $(2002)^{[5]}$, Chiarella, Iori and Perell $(2009)^{[6]}$, Yeh and Yang $(2010,2013)^{[7][8]}$, Li et al.(2014) ${ }^{[9]}$ contribute a lot to the development of the artificial stock market model, research on price limits using simulation method are increasingly getting more and more.

Through the literature review, it can be seen that most of the research on price limits, whether using empirical method or simulation method, focuses on the impact of price limits at a certain threshold on its price, volatility, trading volume and other market indicators, but less attention has been paid to the change of the price limits threshold and the reaction of the market after that. In order to make up for the lack of previous research, this paper will use the method of simulation experiments to explore the multi-level impacts of price limits change on the stock market, and several questions are put up as followed: Will there be a significant increase in stock volatility when the price limits are widened? Will stock liquidity improve significantly? Which threshold is reasonable when considering both volatility and liquidity?

\section{MODEL SETUP}


In designing the artificial stock market, this paper mainly referred to Chiarella and Iori (2002). As a result, the model is based on double auction markets, trading via a central order matching mechanism. Here we assume that agents know the fundamental value of the stock, which is set constant. They also know the historical prices. Then, agents determine their own bid and ask quotes with known information and whether to submit a market or limit order according to a series of exogenous rules. For simplicity, we directly assume that each agent only trades 1 unit of stock each time.

\subsection{Traders' expectations}

Assuming that the agent's expected return at time t consists essentially of three parts: earnings of the fundamental analysis, earnings of the technical analysis, and earnings of the market noise transaction. As is shown in equation (1):

$$
E\left(r_{t+1}^{i}\right)=g_{1}^{i} \cdot \frac{P_{f}-P_{t}}{P_{t}}+g_{2}^{i} \cdot \bar{r}_{L i}+n_{i} \cdot \varepsilon_{t}
$$

The quantities $g_{1}^{i}>0$ and $g_{2}^{i}$ represent the weights given to the fundamentalist and chartist component respectively. The sign of $g_{2}^{i}$ indicates a trend chasing $(>0)$ or contrarian $(<0)$ chartist strategy. The parameters in equation (1) can be regarded as independent random variables, so we assume that: $g_{1}^{i} \sim\left|N\left(0, \sigma_{1}\right)\right|, g_{2}^{i} \sim N\left(0, \sigma_{2}\right), n_{i} \sim N\left(0, n_{0}\right), \varepsilon_{t} \sim N(0,1)$. An agent for whom $g_{1}^{i}=$ $g_{2}^{i}=0$ is a noise trader. The quantity $\bar{r}_{L i}$ is the average of the historical returns over the interval $L_{i}$. The interval selected by each agent may be different, so it can also be seen as an independent random variable, assuming that $L_{i}$ is uniformly distributed over the interval $[1, t]$. As is shown in equation (2):

$$
\bar{r}_{L i}=\frac{1}{L i} \sum_{j=1}^{L i} \frac{P_{t-j}-P_{t-j-1}}{P_{t-j-1}}
$$

Known about the agent's expected return, the agent's expected stock price at time $t+1$ is shown in equation (3):

$$
E\left(P_{t+1}^{i}\right)=P_{t} \cdot e^{E\left(r_{t+1}^{i}\right)}
$$

\subsection{Traders' decision}


If the agent expects a price increase (decrease) he decides to buy (sell) one stock. Assuming that the agent is willing to buy (sell) at a price $b_{t}^{i}\left(a_{t}^{i}\right)$ lower (higher) than his expected future price, the agent's bid and ask quotes based on his expectation are shown in equation (4) and (5):

$$
\begin{aligned}
& b_{t}^{i}=E\left(P_{t+1}^{i}\right) \cdot\left(1-k^{i}\right) \\
& a_{t}^{i}=E\left(P_{t+1}^{i}\right) \cdot\left(1+k^{i}\right)
\end{aligned}
$$

where $k^{i}$ is uniformly distributed over the interval $\left(0, k_{\max }\right)$ with $k_{\max } \leq 1$.

The order book records the bid and ask quotes of each agent, where only the largest bid quote $b_{t}^{q}$ and the smallest ask quote $a_{t}^{q}$ can be acquired by agents. If $b_{t}^{i}\left(a_{t}^{i}\right)$ is smaller (larger) than the largest bid quote $b_{t}^{q}$ (the smallest ask quote $a_{t}^{q}$ ), the agent submits a limit order at $b_{t}^{i}\left(a_{t}^{i}\right)$, otherwise the agent submits a market order at $b_{t}^{q}\left(a_{t}^{q}\right)$.

\subsection{Market mechanism}

The market price of the stock is determined by the orders and quotes submitted by the agents. All orders subject to price priority and time priority are matched and deals are reached. At any time $t$, the price is given by the price at which a transaction occurs, if any. If no new transaction occurs, a proxy for the price is given by the average of the smallest ask quote and the largest bid quote, which is $P_{t}=\left(b_{t}^{q}+a_{t}^{q}\right) / 2$. If no bids or asks are listed in the order book, a proxy for the price is given by the previous price, which is $P_{t}=P_{t-1}$.

Price limits are equivalent to the restrictions on the dynamics of the stock price. As is shown in equation (6):

$$
P_{t} \cdot\left(1-m^{-}\right) \leq P_{t+1} \leq P_{t} \cdot\left(1+m_{+}\right)
$$

where the $m_{+}>0$ and $m_{-}>0$ respectively represent the upper limit and the lower limit. This paper only takes the situation which is $m_{+}=m_{-}$into consideration.

\section{SIMULATION DESIGN AND RESULTS}

Before the simulations, we need to set the parameters of the artificial stock market model. As are shown in Table 1. 
International Journal of Social Science and Economic Research

ISSN: 2455-8834

Volume: 05, Issue: 02 "February 2020"

Table 1: Parameters for simulation

\begin{tabular}{cccc}
\hline Parameter & Parameter meaning & $\begin{array}{c}\text { Reference } \\
\text { value }\end{array}$ & Value range \\
\hline$\sigma_{1}$ & Variance of fundamental strategy distribution & 1 & Constant \\
$\sigma_{2}$ & Variance of technical strategy distribution & 1.4 & Constant \\
$n_{0}$ & Variance of noise transaction distribution & 3 & Constant \\
$k_{\max }$ & The maximum extent of the trader's quote to his expected price & 0.5 & $(0,1]$ \\
$P_{f}$ & Fundamental value of the stock & 1000 & Constant \\
$P_{0}$ & Initial price of the stock & 1000 & Constant \\
$N$ & Numbers of agents & 100 & Constant \\
$T$ & Simulation periods & 2000 & Constant \\
$m$ & Price limits & 0.1 & $(0,+\infty)$ \\
\hline
\end{tabular}

The Monte Carlo simulations are carried out by running the artificial stock market model based on the above parameters. Firstly, this paper simulates the stock prices and the returns without price limits. The simulation results are shown in Figure 1 and Figure 2. Figure 1 shows the time series of the stock prices and the returns without price limits. Figure 2 shows the distribution of the simulated returns in comparison with the normal distribution.
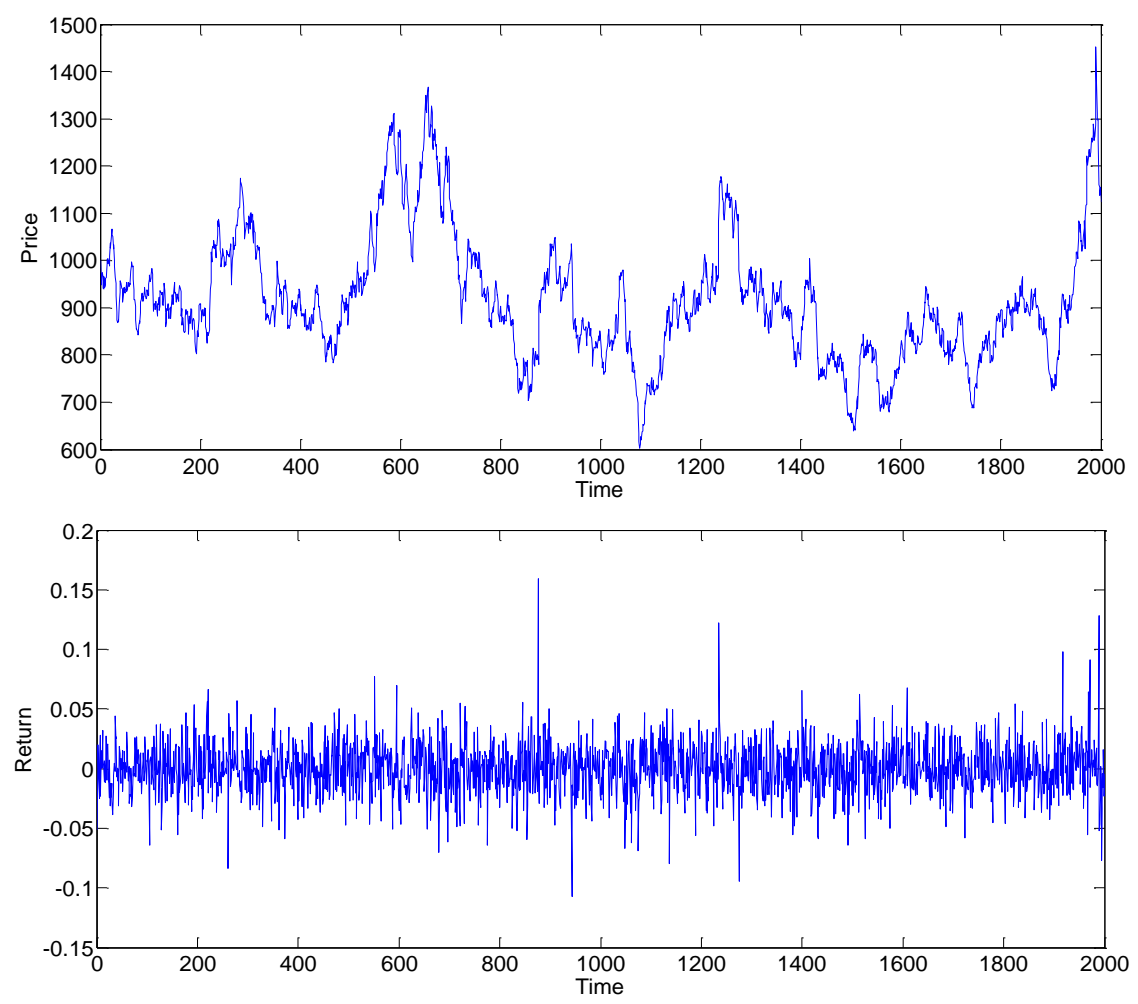

Fig. 1: Time series of the simulation data without price limits 


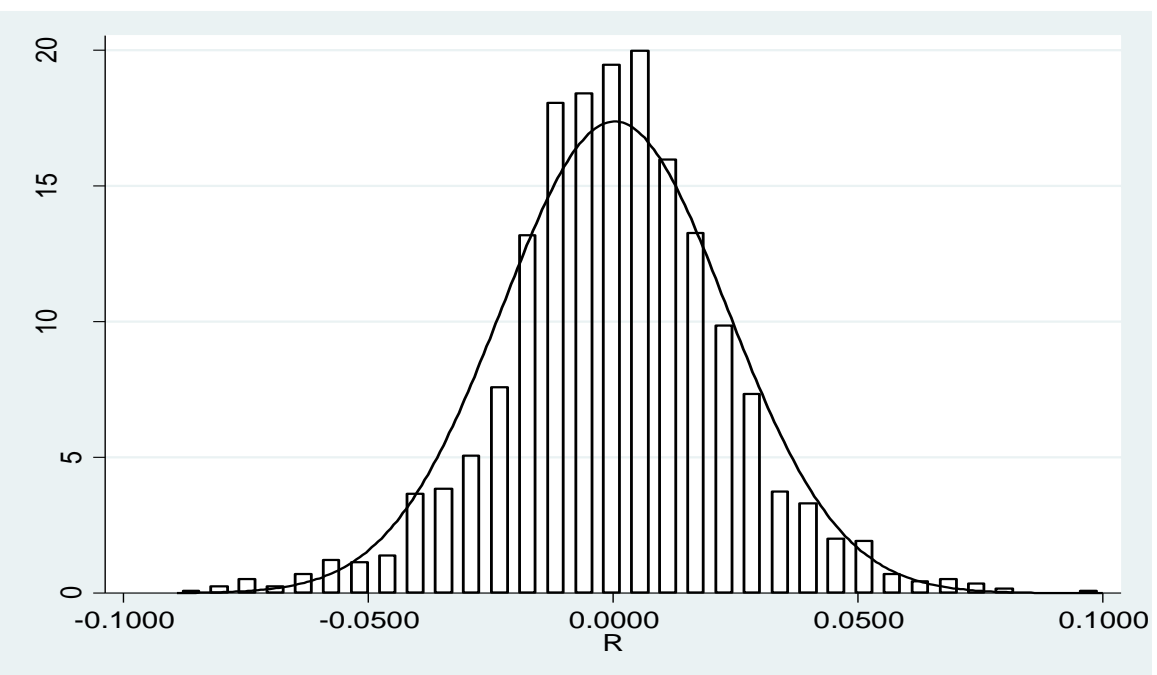

Fig. 2: The distribution of the simulated returns together with the normal distribution

At the same time, the descriptive statistical results of the simulation data are shown in Table 2. In order to verify the substitution of simulation data for real data, in this paper, the daily returns of the CSI 300 (000300), Shanghai Composite Index (000001), SANY Heavy Industry (600031) and China Vanke (000002) since January 1, 2013, are selected as the contrast.

Table 2: The descriptive statistical results of the returns

\begin{tabular}{ccccccc}
\hline & Average & Std. & Skewness & Kurtosis & Jarque-Bera & $H_{|r|}$ \\
\hline Simulated data & 0.1753 & 2.2877 & -0.3047 & 4.8339 & $31.12^{* * *}$ & 0.6023 \\
CSI 300 & 0.1084 & 1.3858 & 0.1649 & 5.7296 & $62.12^{* * *}$ & 0.5914 \\
Shanghai Composite Index & 0.0686 & 1.2592 & -0.0346 & 6.5509 & $103.54 * * *$ & 0.6103 \\
SANY Heavy Industry & 0.3294 & 2.3168 & 0.2782 & 4.1937 & $14.22^{* * *}$ & 0.6261 \\
Vanke & 0.0972 & 1.9917 & 0.1843 & 4.1240 & $11.42^{* *}$ & 0.6212 \\
\hline$* * *, * *, *$ respectively represents rejecting the null hypothesis at 1\%, 5\% and 10\% significance level.
\end{tabular}

In Table 2, the Kurtosis of all the return series is greater than 3, and the Jarque-Bera statistics all reject the normal distribution hypothesis at 5\% significance level. And considering Figure 2, the distribution of the returns produced by this model shows higher probabilities around the mean and the tails compared with the normal distribution, which is similar to the real stock market. Besides, The Hurst exponent of all the return series is all greater than 0.5, which shows that the series is consistent with the stylized facts such as long memory and volatility clustering. Therefore, the simulation data generated by this model as a substitute for real data has a certain feasibility. 


\section{ANALYSIS ON THE INFLUENCE OF PRICE LIMITS CHANGE}

In this section, we set up a number of markets for simulation according to the different price limits, in which case market $\mathrm{A}$ has no price limits, and market $\mathrm{B}$ to $\mathrm{F}$ has price limits threshold of $5 \%, 10 \%, 15 \%, 20 \%$ and $30 \%$ respectively. Then we investigate whether price limits change will affect the volatility and liquidity of stock market. The descriptive statistical results of the simulated returns in different markets are shown in Table 3.

Table 3: The descriptive statistical results of the simulated returns in different markets

\begin{tabular}{ccccccccc}
\hline \multirow{2}{*}{ Market } & $\begin{array}{c}\text { Price } \\
\text { limits }\end{array}$ & Average & Std. & Skewness & Kurtosis & $\begin{array}{c}\text { Jarque- } \\
\text { Bera }\end{array}$ & $H_{|r|}$ & ADF \\
\hline A & N/A & 0.1112 & 2.3858 & 0.3952 & 4.9096 & $35.60 * * *$ & 0.6456 & -13.989 \\
B & $5 \%$ & 0.0826 & 2.0538 & 0.4413 & 3.0005 & $6.49 * *$ & 0.5803 & -13.975 \\
C & $10 \%$ & 0.1753 & 2.2877 & -0.3047 & 4.8339 & $31.12 * * *$ & 0.6023 & -14.232 \\
D & $15 \%$ & 0.1695 & 2.5343 & 0.1749 & 4.2576 & $14.20 * * *$ & 0.7210 & -15.823 \\
E & $20 \%$ & 0.1639 & 2.7790 & 1.0436 & 6.0131 & $111.97 * * *$ & 0.6137 & -13.543 \\
F & $30 \%$ & 0.1079 & 2.9257 & 0.7916 & 5.9600 & $93.90 * * *$ & 0.6500 & -15.28 \\
\hline$* * *, * *, *$ & respectively represents rejecting the null hypothesis at 1\%, 5\% and 10\% significance level.
\end{tabular}

As shown in Table 3, the simulated returns of all markets meet the characteristics of normal distribution such as fat tail, long memory and volatility clustering. Furthermore, the ADF statistics of simulated returns of all market are less than the critical value at $1 \%$ significance level -3.477 , which means that all series are stable.

\subsection{The influence of price limits change on market volatility}

In this paper, we choose the standard deviation of the return series as the indicator to measure market volatility. As shown in Table 3, the volatility conditions of market $\mathrm{B}$ and $\mathrm{C}$ are better than that of market A without price limits, and when price limits go up to $15 \%$ or above, the market volatility will be larger than that of market A without price limits. At the same time, we can draw the conclusion that the market volatility increases with the widening of the price limits.

In order to make the conclusion more accurate, we test the homogeneity of variance of the simulated returns of all markets, and the results are shown in Table 4. 
International Journal of Social Science and Economic Research

ISSN: $2455-8834$

Volume: 05, Issue: 02 "February 2020"

Table 4: The test results of the homogeneity of variance

\begin{tabular}{|c|c|c|c|c|c|c|c|}
\hline Market & $\begin{array}{l}\text { Price } \\
\text { limits }\end{array}$ & A & B & $\mathrm{C}$ & D & $\mathrm{E}$ & $\mathrm{F}$ \\
\hline A & N/A & & $A \gg>B$ & $\approx$ & $\approx$ & $E \gg>A$ & $\mathrm{~F} \gg \gg \mathrm{A}$ \\
\hline B & $5 \%$ & & & $\mathrm{C}>\mathrm{B}$ & $\mathrm{D} \gg>>B$ & $E \gg>B$ & $\mathrm{~F} \gg \gg \mathrm{B}$ \\
\hline $\mathrm{C}$ & $10 \%$ & & & & $\mathrm{D}>\mathrm{C}$ & $E \gg>C$ & $\mathrm{~F} \gg>>C$ \\
\hline $\mathrm{D}$ & $15 \%$ & & & & & $E>D$ & $\mathrm{~F} \gg>\mathrm{D}$ \\
\hline $\mathrm{E}$ & $20 \%$ & & & & & & $\approx$ \\
\hline F & $30 \%$ & & & & & & \\
\hline
\end{tabular}

It can be seen that the volatility of market A without price limits is significantly larger than that of market B (5\% price limits), significantly lower than that of market $\mathrm{E}$ and $\mathrm{F}$ (20\% price limits or above), and not significantly different from that of market $\mathrm{C}$ and $\mathrm{D}$ (10\% and $15 \%$ price limits). In addition, with the rise of the price limits threshold, the market volatility also increases significantly, but under price limits of $20 \%$ or above, the market volatility remains basically stable.

\subsection{The influence of price limits change on market liquidity}

Taking into account the policy objective of the regulators carrying out price limits change to exchange volatility for liquidity, this paper selects the non-liquidity ratio ILLIQ proposed by Amihud (2002) as an indicator of liquidity, while higher values represent lower liquidity. The formula is as follows:

$$
\text { Amihud }=\frac{1}{N} \sum_{t=1}^{N} \frac{\left|r_{t}\right|}{\operatorname{Vol}_{t}}
$$

Table 5 reflects the liquidity situation of all markets and compares that of the simulated markets under different price limits. 
International Journal of Social Science and Economic Research

ISSN: $2455-8834$

Volume: 05, Issue: 02 "February 2020"

Table 5: The liquidity situation of all markets and the comparison

\begin{tabular}{|c|c|c|c|c|c|c|c|c|}
\hline Market & $\begin{array}{l}\text { Price } \\
\text { limits }\end{array}$ & Amihud & A & $\mathrm{B}$ & $\mathrm{C}$ & D & $\mathrm{E}$ & $\mathrm{F}$ \\
\hline A & N/A & 0.2795 & & $\approx$ & $\approx$ & $\mathrm{D}>\mathrm{A}$ & $E \gg \gg A$ & $\mathrm{~F} \gg \gg \mathrm{A}$ \\
\hline B & $5 \%$ & 0.2860 & & & $C>B$ & $\mathrm{D}>\mathrm{B}$ & $E \gg \gg>B$ & $\mathrm{~F} \gg>>\mathrm{B}$ \\
\hline $\mathrm{C}$ & $10 \%$ & 0.2507 & & & & $\approx$ & $E>>C$ & $\mathrm{~F}>>\mathrm{C}$ \\
\hline D & $15 \%$ & 0.2435 & & & & & $\approx$ & $\mathrm{F}>\mathrm{D}$ \\
\hline $\mathrm{E}$ & $20 \%$ & 0.2167 & & & & & & $\approx$ \\
\hline $\mathrm{F}$ & $30 \%$ & 0.2118 & & & & & & \\
\hline
\end{tabular}

It can be seen that market liquidity under price limits of $10 \%$ or above is better than that of market A without price limits, and with the rise of price limits threshold, the market liquidity condition also improves significantly. Through t-test, we can find that there is no significant difference between market $\mathrm{A}$ and market $\mathrm{B}$ or $\mathrm{C}$ (5\% and 10\% price limits), and the market liquidity will be improved significantly under price limits of $15 \%$ or above. At the same time, only when the existing price limits are low, will market liquidity increase significantly with the widening of price limits. For example, when markets with price limits of $10 \%$ or above have a small change in the threshold, the increase in liquidity may not be significant (e.g., $10 \% \rightarrow 15 \%$, $15 \% \rightarrow 20 \%, 20 \% \rightarrow 30 \%)$.

\section{CONCLUSION}

In this paper, an agent-based artificial stock market model driven by investor's orders is constructed, and the stock prices and returns are simulated by setting reasonable parameters. Using the simulated data, this paper further studies the influence of price limits change on the volatility and liquidity of the stock market, and finds that only the strict price limits (e.g., 5\%) can effectively reduce the volatility of the stock market, and at this time there is no significant difference in the market liquidity from that of markets without price limits. Secondly, with the widening of price limits, both market volatility and liquidity will increase significantly, but it is worth noting that when markets with price limits of $10 \%$ or above have a small change in the thresholds, the increase in liquidity may not be that obvious. Eventually, market volatility and liquidity remain basically stable under price limits of $20 \%$ or above. 


\section{REFERENCES}

[1] K. A. Kim and J. Park. Why do price limits exist in stock markets? A manipulation-based explanation [J]. European Financial Management, 2010, 16: 296-318.

[2] Wonse Kim and Sungjae Jun. Effects of a price limit change on market stability at the intraday horizon in the Korean stock market [J]. Applied Economics Letters, 2019, 26 (7): 582-586.

[3] Donald Lien, Pi-Hsia Hung, Jia-De Zhu and Yi-Hsuan Chen. Price limit changes and market quality in the Taiwan Stock Exchange [J]. Pacific-Basin Finance Journal, 2019, 55: 239-258.

[4] F. Westerhoff. Speculative markets and the effectiveness of price limits [J]. Journal of Economic Dynamics and Control, 2003(28): 493-508.

[5] C. Chiarella and G. Iori. A simulation analysis of the microstructure of double auction markets [J]. Quantitative Finance, 2002(2): 346-353.

[6] C. Chiarella, G. Iori and J. Perell. The impact of heterogeneous trading rules on the limit order book and order flows [J]. Journal of Economic Dynamics and Control, 2009, 33: 525-537.

[7] Chia-Hsuan Yeh and Chun-Yi Yang. Examining the effectiveness of price limits in an artificial stock market [J]. Journal of Economic Dynamics \& Control, 2010(34): 20892108.

[8] Chia-Hsuan Yeh and Chun-Yi Yang. Do price limits hurt the market? [J]. Journal of Economic Interaction and Coordination, 2013(8): 125-153.

[9] Li Y, Zhang W, Zhang Y, Zhang X and Xiong X. Calibration of the agent-based continuous double auction stock market by scaling analysis [J]. Information Sciences, 2014, 256: 46-56. 